\title{
Prevalence of Hypertension, Obesity, Diabetes, and Metabolic Syndrome in Nepal
}

\author{
Sanjib Kumar Sharma, ${ }^{1}$ Anup Ghimire, ${ }^{2}$ Jeyasundar Radhakrishnan, ${ }^{3}$ Lekhjung Thapa, ${ }^{1}$ \\ Nikesh Raj Shrestha, ${ }^{1}$ Navaraj Paudel, ${ }^{1}$ Keshar Gurung, ${ }^{1}$ Maskey $R,{ }^{1}$ Anjali Budathoki, ${ }^{1}$ \\ Nirmal Baral, ${ }^{4}$ and David Brodie ${ }^{3}$ \\ ${ }^{1}$ Department of Internal Medicine, B. P. Koirala Institute of Health Sciences, Dharan 76500, Nepal \\ ${ }^{2}$ Department of Public Health and Community Medicine, B. P. Koirala Institute of Health Sciences, Dharan 76500, Nepal \\ ${ }^{3}$ Faculty of Society \& Health, Bucks New University, Buckinghamshire HP11 2JZ, UK \\ ${ }^{4}$ Department of Biochemistry, B. P. Koirala Institute of Health Sciences, Dharan 76500, Nepal
}

Correspondence should be addressed to Sanjib Kumar Sharma, drsanjib@yahoo.com

Received 24 January 2011; Accepted 24 February 2011

Academic Editor: Kazuko Masuo

Copyright (C) 2011 Sanjib Kumar Sharma et al. This is an open access article distributed under the Creative Commons Attribution License, which permits unrestricted use, distribution, and reproduction in any medium, provided the original work is properly cited.

\begin{abstract}
Background. This study was carried out to establish the prevalence of cardiovascular risks such as hypertension, obesity, and diabetes in Eastern Nepal. This study also establishes the prevalence of metabolic syndrome (MS) and its relationships to these cardiovascular risk factors and lifestyle. Methods. 14,425 subjects aged 20-100 (mean $41.4 \pm 15.1$ ) were screened with a physical examination and blood tests. Both the International Diabetic Federation (IDF) and National Cholesterol Education Programme's (NCEP) definitions for MS were used and compared. Results. 34\% of the participants had hypertension, and 6.3\% were diabetic. $28 \%$ were overweight, and $32 \%$ were obese. $22.5 \%$ of the participants had metabolic syndrome based on IDF criteria and $20.7 \%$ according to the NCEP definition. Prevalence was higher in the less educated, people working at home, and females. There was no significant correlation between the participants' lifestyle factors and the prevalence of MS. Conclusion. The high incidence of dyslipidemia and abdominal obesity could be the major contributors to MS in Nepal. Education also appears to be related to the prevalence of MS. This study confirms the need to initiate appropriate treatment options for a condition which is highly prevalent in Eastern Nepal.
\end{abstract}

\section{Introduction}

According to the World Health Organization's recent update [1], diabetes, hypertension, and obesity are one of the top five continuing risk factors for cardiovascular deaths in the world. Obesity is increasing substantially and is one of the major contributors of disease prevalence due to its pathophysiological link to other cardiovascular risks such as hypertension and diabetes. It is estimated that, in 2010, 6.4\% of adults would have diabetes mellitus affecting 285 million in the world and it will increase to $7.7 \%$ by 2030 , affecting 439 million adults [2]. Of special note is that there will be a $67 \%$ increase in the prevalence of diabetes in developing countries from 2010 to 2030 [2].

Metabolic syndrome (MS) is a constellation of overweight/obesity, hypertension, and disturbances of lipid and carbohydrate metabolism. The definition of MS was debated for a long time to produce a standardized clinical criterion. The World Health Organisation describes MS as the presence of type 2 diabetes or impaired glucose tolerance with any two of the following characteristics: obesity, high levels of triglycerides, low levels of high-density lipoprotein, and hypertension. The International Diabetes Federation (IDF) takes central obesity as a prerequisite for the diagnosis of MS with the association of any two of the other factors, that is, high blood pressure, abnormal blood glucose, high levels of triglycerides, and low levels of high-density lipoprotein. Also, the IDF has derived specific reference values for central obesity for different ethnicities. The National Cholesterol Education Programme (NCEP) expert panel on detection, evaluation, and treatment of high blood cholesterol in adults (adult treatment panel, or ATP, III) [3], the National 
Heart, Lung and Blood Institute, and the American Heart Association [4] have released a report on the criteria for diagnosing and managing MS. The panel describes MS as the presence of any three of the following: abdominal obesity, dislipidemia (high levels of triglycerides, low HDL), increased blood pressure, and elevated fasting glucose. This definition has been extensively reviewed and accepted by the greatest number of researchers. For the purpose of this paper, the ATP III and IDF's definitions are used and compared.

Each component of MS is a known risk factor for the development of type 2 diabetes, atherosclerosis, and coronary artery disease (CAD). People with MS are 310 times more likely to develop cardiovascular disease commensurate with a high risk of morbidity and mortality $[5,6]$. Central obesity, one of the components of MS, predicts the occurrence of diabetes and overall cardiovascular risk [7]. The NCEP ATP III [3] states that MS is equal to cigarette smoking as a contributing factor for premature cardiovascular disease.

The prevalence of metabolic syndrome is increasing all over the world with different regions having individual clusters of epidemic risk factors $[6,8]$, and in particular there is evidence of a high prevalence of MS and diabetes in South Asians [9]. Substantial increase in the prevalence of type 2 diabetes in Asia in recent years has raised serious concerns about cardiovascular consequences for these populations $[5,10]$. However, in developing countries, many of these subclinical conditions are not diagnosed until the onset of complications such as myocardial infarction or stroke [11]. It is essential to initiate early detection of these chronic diseases in underdeveloped countries in Asia, such as Nepal, so that preventative action can minimize the consequences.

This study aims to establish the prevalence of hypertension, diabetes, obesity, and metabolic syndrome in the participants of a major health screening programme in Nepal. This study also aims to establish the relationship between the components of MS and lifestyle of the participants.

\section{Methods}

2.1. Subjects. Nepal is one of the poorest countries of the world at the 136th position of human development index. The total population of Nepal is 27 million. The subjects were the participants of the "Programme for Detection and Management of Chronic Kidney Disease, Hypertension, Diabetes and Cardiovascular Disease," a community-based screening programme in Eastern Nepal [12].

2.2. Research Team and Demographic Data Collection. In this community-based programme a series of community awareness programmes were conducted in a specific locality with the help of local leaders, medical students, and community volunteers. Various screening centres such as permanent centers (in health clinics, community centers, etc.) and temporary screening centers (in schools, clubs, houses of worship, and private homes) were used to screen the population. Each center used a group of five to seven people as community volunteers and consisted of a local leader (priest, administrator, school teachers, and local political leaders), a laboratory technician, and nurse. Medical students (approximately 100 in number) and nursing students (around 25) assisted the community volunteers.

Prior to screening, the community volunteers went from door to door to record the number of family members residing permanently and to inform the members of the family, about the need of the project. All people of $\geq 20$ years were invited to come to a predefined place in very close vicinity to their house. They were requested to avoid food for the previous 12 hours. Pregnant or menstruating women at the time of analysis, people with a fever or acute illness, and those who had recently engaged in heavy exercise were excluded.

The research team also collected general information on the participants' demographic data, diet, smoking, alcohol consumption, and physical activity. The data recorded included family and medical history for kidney disease, high blood pressure, diabetes, cardiovascular disease and any current medication or treatment.

2.3. Physiological Measurements. Blood pressure was measured by the auscultatory method with a random zero mercury sphygmomanometer and standard cuff $(12 \times 34 \mathrm{~cm})$. The blood pressure measurement was taken in the seated position, quietly in a chair with feet on the floor and an arm support at the heart level.

Hypertension was defined according to the guidelines of the Seventh Report of the Joint National Committee on Prevention, Detection, Evaluation and Treatment of High Blood Pressure [13], that is, systolic blood pressure $\geq$ $140 \mathrm{~mm} \mathrm{Hg}$ or diastolic blood pressure $\geq 90 \mathrm{~mm} \mathrm{Hg}$ and/or concomitant use of antihypertensive medications. Body weight and height were assessed with all subjects standing without shoes and heavy outer garments to the nearest $0.1 \mathrm{~kg}$ and $1 \mathrm{~cm}$, respectively. Body mass index was estimated according to standard nomograms. Waist circumference was measured over light clothing at a level midway between the lower rib margin and the iliac crest in centimetres rounded up to nearest $0.5 \mathrm{~cm}$. Abdominal obesity is defined as an abdominal circumference $>102 \mathrm{~cm}$ (40 in) in males and $>$ $88 \mathrm{~cm}$ (35 in) in females for NCEP criteria and $>90 \mathrm{~cm}$ in males and $>80 \mathrm{~cm}$ in females for IDF criteria for South Asians.

Plasma glucose concentration was determined by the glucose oxidase-peroxidase method (Vitalab Selectra-2, Merck, Germany). The diagnosis of diabetes was defined by either casual plasma glucose $\geq 200 \mathrm{mg} \cdot \mathrm{dL}^{-1}$ associated with symptoms of diabetes and on fasting samples-plasma glucose $\geq$ $126 \mathrm{mg} \cdot \mathrm{dL}^{-1}$. Individuals with self reported, prior physiciandiagnosis of diabetes were classified as having previously diagnosed diabetes.

Serum lipids that include total cholesterol, high-density lipoprotein (HDL), low-density lipoprotein (LDL), and triglycerides (TG) were also measured (Vitalab Selectra-2, Merck, Germany). 
2.4. Quality Control. The results from any person having a history of hypertension or found to have hypertension were verified by qualified doctors. All biochemical abnormalities were reconfirmed. The biochemical tests were completed in semiautomatic analysers (Microlab 300, Vital Scientific, The Netherelands). The tests were undertaken in the same machine using standard biochemical reagents. Regular internal quality controls were undertaken and routinely crosschecked with other laboratories.

2.5. Data Handling. Data were stored in a central electronic database using "Epidata" software. Epidata refers to a group of applications used in combination for creating documented data structures and analysis of quantitative data. In this study, Epidata was used for simple and programmed data entry and data documentation.

2.6. Data Analysis. Data were extracted from "Epidata" and imported to SPSS 18.0 software. The data were recoded as necessary, and frequencies were analysed. The IDF and NCEP ATP III's criteria for metabolic syndrome were used to calculate and compare the frequency of metabolic syndrome. The NCEP criterion was used to find the correlations with other findings. The relationships between the prevalence of cardiovascular risk factors, demographic details, lifestyle, and physiological test results were analysed using the Spearman correlation test. Further, the differences in the categorical variables were examined using chi-squared test. Odds Ratios (ORs) and their 95\% confidence interval were calculated using binary logistic regression (for gender and age) and multinomial logistic regression (for life style factors).

\section{Results}

In total, 14,425 people, aged 20-100 (mean age $41.4 \pm 15.1$ ), were included in the study. Among them, 99.9\% were South Asians who were living in Nepal.

The participants' demographic and lifestyle details are listed in Table 1. The participants were a mixture of various levels of education. The percentage of education level is illustrated in accordance to the number of years in education (1-5 years-primary, 6-10 years-secondary, $>10$ yearshigher secondary level). The participants were divided into four categories according to their work: labourer/farm, office, house, and none/unknown. The age was divided into four categories. Participants' physical activities were defined according to the time spent every day on physical activity as $>60 \mathrm{~min}, 30-60 \mathrm{~min},<30 \mathrm{~min} /$ day, and none. This information was recorded verbally.

3.1. Obesity, Diabetes, and Hypertension. Abdominal obesity was observed in $11.5 \%(n=1607 / 14002)$ of the participants as per NCEP criteria (mean waist circumference: male$107.38 \pm 6.19 \mathrm{~cm}$, female- $94.84 \pm 5.84 \mathrm{~cm}$ ) and in $34.7 \%$ ( $n=5006 / 14418)$ of the participants as per IDF criteria. According to the revised BMI, $10.6 \%$ ( $n=1534 / 14423)$ were underweight (BMI < 18.5), 28.2\% $(n=4065 / 14423)$ were

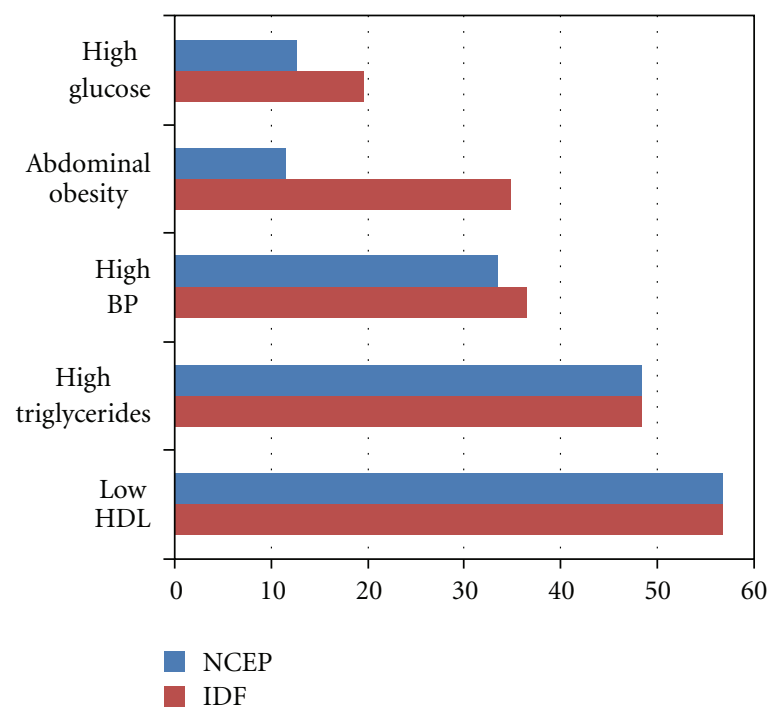

Figure 1: Percentage of traits of metabolic syndrome in the total participants.

overweight $(\mathrm{BMI}=22-24.9)$, and $32.5 \%(n=4689 / 14423)$ were obese $(\mathrm{BMI}>25)$ [14].

Diabetic prevalence was $6.3 \%(889 / 14008)$ of which $4.8 \%(n=673 / 14008)$ were under treatment. A figure of $12.3 \%(n=1718 / 14009)$ had a family history of diabetes. Hypertension was observed in 33.9\% $(n=4894 / 14422)$ of the participants (mean systolic $138.72 \pm 18.03 \mathrm{~mm} \mathrm{Hg}$ and mean diastolic $93.09 \pm 8.45 \mathrm{~mm} \mathrm{Hg}$ ). Only $12.9 \%$ $(1812 / 14009)$ were previously diagnosed, and $8.5 \%$ were receiving treatment for hypertension. A history of coronary artery disease was present in $1.6 \%(n=218 / 14007)$, and $1 \%$ $(n=142)$ were under treatment for ischemic heart disease or stroke.

Table 2 shows the goodness of fit for the prevalence of obesity, hypertension, and diabetes. The comparison was against the latest available prevalence data [15-17]. Prevalence of hypertension showed no difference from these data, and obesity showed only a small difference. Diabetes showed a large statistically significant difference from the previous available data.

The percentages of the participants who had abnormal lipid profile that includes total serum cholesterol, serum LDL cholesterol, serum HDL cholesterol, serum triglycerides are listed in Table 3.

3.2. Prevalence of Metabolic Syndrome. There were 2191 sets of data eligible to meet the criteria for metabolic syndrome. MS was observed in $22.5 \%(n=494 / 2191)$ of the participants according to the IDF criteria and $20.7 \%$ (454/2191) according to the NCEP criteria. The percentages of individual MS risk factors among the total participants and the participants with MS are illustrated in Figures 1 and 2. Generally, among the total participants and the specific participants with MS, the presence of abnormal lipids was higher than the other factors defining MS. However, 
TABle 1: Demographic and lifestyle details of the participants.

\begin{tabular}{|c|c|}
\hline Demographic detail & $\%$ in total participants \\
\hline \multirow{4}{*}{ Age $(n=14425)$} & $20-40$ years- $53.6 \%(n=7729)$ \\
\hline & $41-60$ years $-33.8 \%(n=4880)$ \\
\hline & $61-80$ years $-11.9 \%(n=1716)$ \\
\hline & $80-100$ years $-0.7 \%(n=100)$ \\
\hline \multirow{2}{*}{ Gender $(n=14009)$} & Male- $38 \%(n=5327)$ \\
\hline & Female- $62 \%(n=8682)$ \\
\hline \multirow{4}{*}{ Level of education $(n=14009)$} & Higher secondary-33.1\% $(n=4635)$ \\
\hline & Secondary—22\% $(n=3079)$ \\
\hline & Primary-14.9\% $(n=2092)$ \\
\hline & None- $30 \%(n=4197)$ \\
\hline \multirow{4}{*}{ Work category $(n=13982)$} & Labour-12.9\% $(n=1797)$ \\
\hline & House $-57.1 \%(n=7977)$ \\
\hline & Office- $-14.9 \%(n=2090)$ \\
\hline & None $-15.1 \%(n=2118)$ \\
\hline \multirow{3}{*}{ Physical activity ( $n=14001)$} & $>60 \mathrm{~min} /$ day $-37.1 \%(n=5190)$ \\
\hline & $30-60 \mathrm{~min} /$ day $-25.3 \%(n=3543)$ \\
\hline & $<30 \mathrm{~min} /$ day or None $-37.6 \%(n=5628)$ \\
\hline \multirow{3}{*}{ Fruits and vegetables in diet $(n=14009)$} & Everyday-31.4\% $(n=4403)$ \\
\hline & $1-5$ days $-56 \%(n=7842)$ \\
\hline & Once/week or None-12.6\% $(n=1764)$ \\
\hline \multicolumn{2}{|l|}{ Smoking $(n=14004)$} \\
\hline \multirow{3}{*}{ Current-11.9\% $(n=1673)$} & $>10$ years $-8.5 \%$ \\
\hline & $1-10$ years $-32.3 \%$ \\
\hline & $<1$ year- $59.2 \%$ \\
\hline \multicolumn{2}{|l|}{ Previous-8.8\% $(n=1232)$} \\
\hline \multicolumn{2}{|l|}{ Alcohol consumption $(n=13998)$} \\
\hline \multirow{3}{*}{ Total-24.8\% } & Every day-6\% $(n=838)$ \\
\hline & Once/week—9.5\% $(n=1189)$ \\
\hline & Once/month-9.3\% $(n=1306)$ \\
\hline
\end{tabular}

TABLE 2: Chi-squared "goodness of fit" for the prevalence of cardiac risk factors in participants.

\begin{tabular}{lcccc}
\hline Category & & Observed $n$ & Expected $n$ & Chi-squared significance $(P)$ \\
\hline \multirow{2}{*}{ Obesity $(n=14423)$} & No & 9734 & 9605.7 & $.024^{*}$ \\
& Yes & 4689 & 4817.3 & 9547.4 \\
Hypertension $(n=14422)$ & No & 9528 & 4874.6 & .733 \\
& Yes & 4894 & 13461.7 & $.001^{* *}$ \\
Diabetes $(n=14008)$ & No & 13119 & 546.3 & \\
& Yes & 889 & & \\
\hline
\end{tabular}

${ }^{* *}$ Significant at the .01 level ( 2 tailed).

* Significant at the .05 level (2 tailed).

TABle 3: Percentage of participants' abnormal lipid profile.

\begin{tabular}{lccc}
\hline & Percentage among participants & Mean $\left(\mathrm{mg} \cdot \mathrm{dL}^{-1}\right)$ & Reference Value $\left(\mathrm{mg} \cdot \mathrm{dL}^{-1}\right)[18]$ \\
\hline High cholesterol & $17.2 \%(n=1663 / 9696)$ & $227.9 \pm 34.06$ & $>200$ \\
High LDL & $36.2 \%(n=791 / 2188)$ & $129.91 \pm 27.09$ & $>100$ \\
Low HDL & $56.7 \%(n=1242 / 2192)$ & Male $-33.63 \pm 3.83$ & Male $<40$ \\
High triglycerides & $48.3 \%(n=4681 / 9689)$ & Female $-39.08 \pm 5.71$ & Female $<50$ \\
\end{tabular}




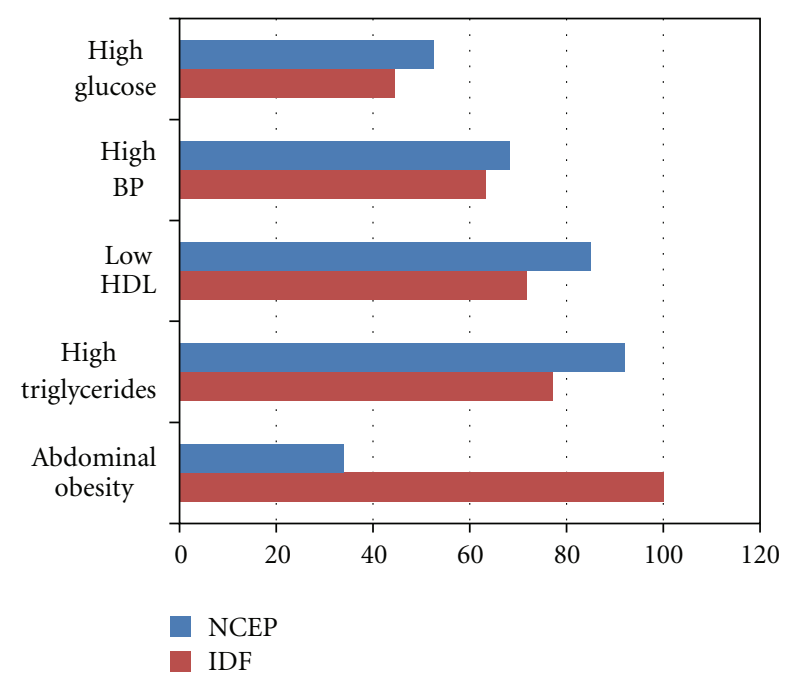

FIGURe 2: Percentage of individual risk factor among participants with MS.

the presence of abdominal obesity was higher among MS participants using IDF criteria (Figure 2).

Table 4 provides the MS prevalence in relation to demographic and lifestyle factors. The females had a higher prevalence of MS than males. According to the NCEP criteria, the age groups $41-60$ and $61-80$ had a higher prevalence of MS than the lower age group. According to IDF criteria, the age groups $41-60$ and $20-40$ had a higher prevalence of MS. The prevalence of MS was higher in participants with less education. The participants who worked at home had a high incidence of MS according to both the criteria used. The sedentary group had a higher incidence of MS than the participants who were physically active.

The univariate correlations between cardiac risk factors are shown in Table 5, and the chi-squared independence of them in the metabolic syndrome prevalence is listed in Table 6.

The prevalence of MS (NCEP scores) had a significant positive relationship with education levels and physical activity. There were significant positive correlations between physical activity and the three individual MS components: high glucose $(r=0.03, P<.01)$, high $\mathrm{BP}(r=0.04$, $P<.01)$, and low HDL $(r=0.23, P<.01)$. There was no correlation between physical activity and the other two MS components: high triglyceride $(r=0.003, P>.05)$ and abdominal obesity $(r=-0.003, P>.05)$. There was no relationship with diet and work. The NCEP scores had a positive correlation between the family history of diabetes $(r=0.83, P<.01)$ and hypertension $(r=0.115, P<$ $.01)$. Although a number of these correlations show high levels of significance, the common variance is extremely low, suggesting that the sample size is having a major impact on the significance. As a result of this, we do not propose to develop this outcome in any great detail.

Table 7 lists the chi-squared independence, odds ratios, and confidence intervals in the association between age, gender, and specific lifestyle factors in metabolic syndrome prevalence. Gender, age, education level, and physical activity show a positive association with the prevalence of metabolic syndrome.

\section{Discussion}

It is important to observe the prevalence of diabetes, hypertension, and obesity individually and also the combination of risk factors as metabolic syndrome to predict the risk of cardiovascular disease. Any association between lifestyle factors and these risk factors would provide the opportunity to encourage a change in lifestyle to promote lower levels of subsequent CVD.

4.1. Education, Work, and Physical Activity. The large number of poorly educated people and the large number of school dropouts could be linked to the disease prevalence. The prevalence of hypertension and metabolic syndrome in poorly educated people was large when compared with the educated participants. Though the results are not generalized, the relationship between education levels and the prevalence of hypertension agrees with earlier studies $[19,20]$. These found that education levels significantly influence the knowledge of hypertension and the awareness of cardiovascular risk. This suggests that there is a need to improve the awareness of health and use education to prevent or reduce the risk of MS and cardiovascular risks in these groups. The office workers had a lower prevalence of MS (NCEP scores) than the other groups. A considerable number of office workers (64\%) undertook regular physical activity of more than $30 \mathrm{~min} /$ day. This may be due to health awareness gained from higher education. Most of the poorly educated or less educated people were labourers or home workers. The labourers had a lower MS prevalence than the home workers. The home workers education levels and physical activities were comparatively lower than the other work groups. These findings clearly show that education and physical activity have an influence on the prevalence of MS. Most of the females were home workers (75.5\%), and their education was comparatively lower than the males. This may be the reason for the higher prevalence of MS in females. The amount of physical activity involved in home workers is unknown, but the results suggest it is less than that undertaken by other workers.

Asian populations continue to modernize, and levels of physical activity are declining as (i) home and work place jobs become more automated and sedentary and (ii) transportation is more readily available [7]. The prevalence of MS among the participants who had no physical activity was surprisingly no different than others. This may be due to a higher than average number of missing values in these data (2191/14425 complete data to meet the criteria for MS) or to other unknown socioeconomic factors.

4.2. Diet and Age. Controversially, there was a high prevalence of MS among people who regularly ate fruit and vegetables. Lee et al. [21] found that a higher intake of 
TABLE 4: Demographic details and prevalence of metabolic syndrome and other risks.

\begin{tabular}{|c|c|c|c|c|c|c|}
\hline & \multicolumn{6}{|c|}{ Disease prevalence in participant category } \\
\hline & & Obesity/overweight & Diabetes & Hypertension & MS-NCEP criteria & MS_-IDF criteria \\
\hline \multirow{4}{*}{ Gender } & \multirow{2}{*}{ Male } & $59.1 \%$ & $8.1 \%$ & $40.7 \%$ & $18.6 \%$ & $17.1 \%$ \\
\hline & & $n=3146 / 5327$ & $n=429 / 5326$ & $n=2164 / 5327$ & $n=150 / 805$ & $n=138 / 805$ \\
\hline & \multirow{2}{*}{ Female } & $61.8 \%$ & $5.3 \%$ & $30.0 \%$ & $21.9 \%$ & $25.7 \%$ \\
\hline & & $n=5360 / 8680$ & $n=460 / 8682$ & $n=2603 / 8679$ & $n=304 / 1386$ & $n=356 / 1386$ \\
\hline \multirow{8}{*}{ Age group } & \multirow{2}{*}{ 20-40 Years } & $55.5 \%$ & $1.9 \%$ & $19.6 \%$ & $9.8 \%$ & $13.1 \%$ \\
\hline & & $n=4293 / 7727$ & $n=140 / 7519$ & $n=1514 / 726$ & $n=110 / 1124$ & $n=147 / 1124$ \\
\hline & \multirow{2}{*}{ 41-60 Years } & $70.5 \%$ & $10.2 \%$ & $46.1 \%$ & $31.4 \%$ & $34.7 \%$ \\
\hline & & $n=3440 / 4880$ & $n=480 / 4727$ & $n=2252 / 4880$ & $n=256 / 815$ & $n=283 / 815$ \\
\hline & \multirow{2}{*}{$61-80$ Years } & $56.7 \%$ & $15.4 \%$ & $62 \%$ & $34.8 \%$ & $25.1 \%$ \\
\hline & & $n=973 / 1716$ & $n=257 / 1664$ & $n=1064 / 1726$ & $n=86 / 247$ & $n=62 / 247$ \\
\hline & \multirow{2}{*}{ 80-100 Years } & $48 \%$ & $12.2 \%$ & $64 \%$ & $40 \%$ & $40 \%$ \\
\hline & & $n=48 / 100$ & $n=12 / 98$ & $n=64 / 100$ & $n=2 / 5$ & $n=2 / 5$ \\
\hline \multirow{8}{*}{$\begin{array}{l}\text { Level of } \\
\text { education }\end{array}$} & \multirow{2}{*}{ Higher Secondary } & $59.9 \%$ & $5.1 \%$ & $27.2 \%$ & $13.3 \%$ & $15.8 \%$ \\
\hline & & $n=2775 / 4634$ & $238 / 4634$ & $n=1262 / 4633$ & $n=117 / 880$ & $139 / 880$ \\
\hline & \multirow{2}{*}{ Secondary } & $64.1 \%$ & $5.3 \%$ & $27.8 \%$ & $19.2 \%$ & $22.2 \%$ \\
\hline & & $n=1972 / 3098$ & $n=163 / 3079$ & $n=857 / 3078$ & $n=69 / 360$ & $80 / 360$ \\
\hline & \multirow{2}{*}{ Primary } & $63.9 \%$ & $8.3 \%$ & $38.3 \%$ & $22.7 \%$ & $25.5 \%$ \\
\hline & & $n=1337 / 2092$ & $n=174 / 2092$ & $n=802 / 2092$ & $90 / 396$ & $101 / 396$ \\
\hline & \multirow{2}{*}{ None } & $57.6 \%$ & $7.5 \%$ & $44.0 \%$ & $32.1 \%$ & $31.4 \%$ \\
\hline & & $n=2419 / 4197$ & $n=314 / 4197$ & $n=1847 / 4197$ & $n=178 / 555$ & $174 / 555$ \\
\hline \multirow{8}{*}{ Work category } & \multirow{2}{*}{ Labour } & $56.5 \%$ & $5.3 \%$ & $35.4 \%$ & $17.9 \%$ & $17 \%$ \\
\hline & & $n=1015 / 1797$ & $n=96 / 1997$ & $n=636 / 1797$ & $n=40 / 224$ & $n=38 / 224$ \\
\hline & \multirow{2}{*}{ Office } & $69.3 \%$ & $7.8 \%$ & $34.7 \%$ & $16 \%$ & $21.5 \%$ \\
\hline & & $n=1448 / 2089$ & $n=162 / 2090$ & $n=724 / 2089$ & $n=58 / 362$ & $n=78 / 362$ \\
\hline & \multirow{2}{*}{ House } & $69.3 \%$ & $6.3 \%$ & $34 \%$ & $23.9 \%$ & $25.1 \%$ \\
\hline & & $n=1448 / 2089$ & $n=506 / 7976$ & $n=2712 / 7975$ & $n=303 / 1269$ & $n=318 / 1269$ \\
\hline & \multirow{2}{*}{ None } & $50.2 \%$ & $5.8 \%$ & $32.6 \%$ & $15.8 \%$ & $17.5 \%$ \\
\hline & & $n=1064 / 2118$ & $n=122 / 2118$ & $n=690 / 2118$ & $n=53 / 336$ & $n=60 / 336$ \\
\hline \multirow{8}{*}{ Physical activity } & \multirow{2}{*}{$>60 \mathrm{~min} /$ day } & $62 \%$ & $5.2 \%$ & $29.6 \%$ & $22.3 \%$ & $24.2 \%$ \\
\hline & & $n=3215 / 5188$ & $n=270 / 5190$ & $n=1535 / 5187$ & $n=79 / 355$ & $n=86 / 355$ \\
\hline & \multirow{2}{*}{$30-60 \mathrm{~min} /$ day } & $62.8 \%$ & $8.2 \%$ & $37.6 \%$ & $23.6 \%$ & $25.0 \%$ \\
\hline & & $n=2226 / 3543$ & $n=291 / 3542$ & $n=1333 / 3543$ & $n=154 / 653$ & $n=163 / 653$ \\
\hline & \multirow{2}{*}{$<30 \mathrm{~min} /$ day } & $59.1 \%$ & $6.9 \%$ & $36.9 \%$ & $25.4 \%$ & $26.3 \%$ \\
\hline & & $n=1805 / 3053$ & $n=212 / 3053$ & $n=1128 / 3053$ & $n=171 / 674$ & $n=177 / 674$ \\
\hline & None & $56.7 \%$ & $5.1 \%$ & $34.8 \%$ & $9.8 \%$ & $13.4 \%$ \\
\hline & 10010 & $n=1805 / 3053$ & $n=114 / 2215$ & $n=770 / 2215$ & $n=50 / 509$ & $n=68 / 509$ \\
\hline & Every day & $61.0 \%$ & $7.4 \%$ & $32.2 \%$ & $23.2 \%$ & $23.5 \%$ \\
\hline & & $n=2686 / 4401$ & $n=325 / 4403$ & $n=1416 / 4400$ & $n=68 / 293$ & $n=69 / 293$ \\
\hline & 3-5 davs/week & $61.3 \%$ & $5.8 \%$ & $34.0 \%$ & $20.3 \%$ & $23.6 \%$ \\
\hline $\begin{array}{l}\text { Fruits and } \\
\text { vegetable }\end{array}$ & 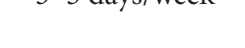 & $n=4804 / 7842$ & $n=451 / 7841$ & $n=2664 / 7842$ & $n=326 / 1604$ & $n=378 / 1604$ \\
\hline in diet & Once/week & $58.1 \%$ & $6.0 \%$ & $38.3 \%$ & $21.0 \%$ & $16.9 \%$ \\
\hline & & $n=947 / 1630$ & $n=97 / 1630$ & $n=637 / 1630$ & $n=57 / 272$ & $n=46 / 272$ \\
\hline & None & $51.5 \%$ & $11.9 \%$ & $41.0 \%$ & $13.6 \%$ & $4.5 \%$ \\
\hline & & $n=69 / 134$ & $n=16 / 134$ & $n=55 / 134$ & $n=3 / 22$ & $n=1 / 22$ \\
\hline
\end{tabular}

macronutrients such as fruits and vegetables is associated with general obesity. However, it is not clear how the vegetables and fruits were eaten, for example, overcooked, processed, and so forth. The exact quantity of the dietary intake was not recorded as it was not the primary area of focus of the study. In these populations, several dietary imbalances have been reported in previous studies. These tend to report a low intake of mono-unsaturated fats 
TABLE 5: Relationship between the prevalence of MS and other cardiovascular risks.

\begin{tabular}{|c|c|c|c|c|}
\hline & & Hypertension & Diabetes & Metabolic syndrome \\
\hline Obesity & & $.150^{* *}$ & $.070^{* *}$ & $.153^{* *}$ \\
\hline Hypertension & Spearman's correlation coefficient & & $.101^{* *}$ & $.234^{* *}$ \\
\hline Diabetes & & & & $.384^{* *}$ \\
\hline
\end{tabular}

** Correlation is significant at the .01 level (2 tailed).

TABLE 6: Chi-squared independence of cardiac risk factors in the prevalence metabolic syndrome $(n=2191)$.

\begin{tabular}{lccc}
\hline & Hypertension & Obesity & Diabetes \\
\hline Metabolic syndrome & $31.9 \% n=292 / 914$ & $34.8 \% n=241 / 693$ & $58.6 \% n=78 / 133$ \\
Significance $(P)$ & $.001^{* *}$ & $.001^{* *}$ & $.001^{* *}$ \\
\hline$* *$
\end{tabular}

${ }^{* *}$ Correlation is significant at the .01 level (2 tailed).

(MUFAs), n-3 polyunsaturated fats (PUFA), and transfatty acids (mostly related to widespread use of vanaspati, a hydrogenated oil) [9]. The healthy traditional plant-based diets are being replaced by cheaper calorie dense high-fat foods. These changes are resulting in a rapid increase in the prevalence of obesity throughout Asia and the subsequent development of MS [8]. Ness and Powles also found in their review [22] that many studies were reporting the null or negative effects of fruit and vegetable intake on the prevalence of cardiovascular diseases. However, the correlations found in those studies were generally low, as seen in our study. Further, they suggest that a food-based analysis would complement the nutrient-based analysis to clarify these issues [22]. In Nepal, the regular diet in addition to fruits and vegetables, that is, such as rice, which is high in carbohydrates, and the methods of cooking may be dietary causes of metabolic syndrome.

The age groups 40-60 had a large prevalence of MS in this study. Also, it is important to note that this middleaged group had a high incidence of overweight or general obesity and abdominal obesity. The other age groups had a lower prevalence of MS than the 40-60 years old, yet it was still relatively high. This included the younger population (20-40 yrs) at nearly $10 \%$. Inadequate maternal nutrition in pregnancy, low birth weight, and childhood obesity may be important factors for the development of metabolic syndrome and diabetes [9]. Specifically in children and young individuals, a high intake of n-6 PUFA is correlated with hyperinsulinaemia. In adults, high carbohydrate meal consumption is related to hyperinsulinaemia, postprandial hyperglycaemia, and hypertriacylglycerolaemia [9].

4.3. Obesity and Lipids. Unger described metabolic syndrome as "a failure of the system of intracellular lipid homeostasis which prevents lipotoxicity in organs of overnourished individuals" [23]. In this study, a large number of participants had increased triglycerides levels and low HDL levels. In addition to low levels of HDL, the HDL particles are small, dense, and dysfunctional in South Asians [24]. These are strong predictors of cardiovascular disease. Hypertriglyceridaemia is a direct reflection of an insulin resistance condition, and it is interrelated to the low HDL concentrations in developing endothelial dysfunction [25].
In Nepal, a high number of the participants had abdominal obesity and were overweight/obese, according to their BMI. The BMI is a simple useful measure for overall abnormal weight, yet not a standard measure for obesity. BMI cannot differentiate between whether the condition was due to unusual muscular development or the accumulation or distribution of fat in the body [26, 27]. Despite the low prevalence of general body obesity compared to western countries, metabolic syndrome is growing into a significant public health problem in Asia [28]. This may be mainly due to the large number of people with central obesity, a feature which was also observed in this study. The higher prevalence of MS in females is also more likely to be due to a higher incidence of abdominal obesity. Abdominal obesity is an important factor because metabolic syndrome and increased abdominal fat are related to a reduction of adiponectin, an adopicyte-derived hormone with antiatherogenic and antiinflammatory properties [29]. The abdominal adipose tissue results in release of free fatty acids directly in the portal veins and altered lipid levels in the blood [30]. Further abdominal adiposity increases insulin secretion, and it would be exaggerated by decreased hepatic clearance leading to hyperinsulinemia [31]. The free fatty acid release also results in endothelial dysfunction that develops hypertension. Thus abdominal obesity is an important indicator of cardiovascular disease due to its link to dyslipidemia, hyperinsulinemia, hypertension, and impaired fibrinolytic capacity [32].

4.4. IDF versus NCEP Definitions. Tan et al. [33] state that if the NCEP's criteria were applied to the Asian population, it might underestimate the prevalence of metabolic syndrome and the risk of cardiovascular disease. So a reduced cutoff point for abdominal obesity for Asians was suggested. IDF's specific reference values for abdominal obesity make a substantial difference to the prevalence of MS between the two criteria. The IDF's cut-off points for South Asians' waist circumference are lower than the NCEP's general cut-off points ( $\geq 90 \mathrm{~cm}$ versus $\geq 102 \mathrm{~cm}$ in men and $\geq 80 \mathrm{~cm}$ versus $\geq 88 \mathrm{~cm}$ in women). Another study on Chinese population also found a large increase in the prevalence of metabolic syndrome using IDF criteria compared with NCEP criteria [34]. However, in our study both definitions demonstrated a higher prevalence of metabolic syndrome (20.7-22.5\%) 
TABLE 7: Chi-squared significance for the independence, odds ratios and $95 \%$ confidence interval of age, gender and life style factors in the prevalence of metabolic syndrome.

\begin{tabular}{|c|c|c|c|c|}
\hline & Chi-squared independence Sig $(P)$ & Odds ratio (ORs) & 95\% confidence interval & ORs Sig $(P)$ \\
\hline Gender & .066 & 1.403 & $1.115-1.766$ & $.004^{*}$ \\
\hline Age & $.001^{* *}$ & 1.052 & $1.044-1.060$ & $.001^{* *}$ \\
\hline \multicolumn{5}{|l|}{ Education level } \\
\hline Higher secondary & \multirow{4}{*}{$.001^{* *}$} & 1.348 & $0.951-1.910$ & .093 \\
\hline Secondary & & 0.990 & $0.691-1.419$ & .957 \\
\hline Primary & & 1.368 & $1.002-1.867$ & $.049 *$ \\
\hline None & & \# & \# & \# \\
\hline \multicolumn{5}{|l|}{ Work } \\
\hline Labour & \multirow{4}{*}{$.001^{* *}$} & 1.101 & $0.676-1.796$ & 699 \\
\hline Office & & 0.945 & $0.594-1.503$ & .810 \\
\hline House & & 0.739 & $0.517-1.057$ & .098 \\
\hline None & & \# & \# & \# \\
\hline \multicolumn{5}{|l|}{ Fruit/Veg in diet } \\
\hline Everyday & \multirow{4}{*}{.585} & 0.725 & $0.199-2.638$ & .625 \\
\hline 3-5 days/week & & 0.843 & $0.238-2.993$ & .792 \\
\hline Once a week & & 0.960 & $0.262-3.520$ & .951 \\
\hline None & & \# & \# & \# \\
\hline \multicolumn{5}{|l|}{ Smoking } \\
\hline Current & \multirow{3}{*}{$.005^{* *}$} & 0.968 & $0.651-1.439$ & .871 \\
\hline Former & & 0.870 & $0.584-1.295$ & .493 \\
\hline Never & & \# & \# & \# \\
\hline \multicolumn{5}{|l|}{ Physical activity } \\
\hline$>60 \mathrm{~min} /$ day & \multirow{4}{*}{$.001^{* *}$} & 0.369 & $0.246-0.553$ & $.001^{*}$ \\
\hline $30-60 \mathrm{~min} /$ day & & 0.351 & $0.245-0.502$ & $.001^{*}$ \\
\hline$<30 \mathrm{~min} /$ day & & 0.337 & $0.236-0.479$ & $.001^{*}$ \\
\hline None & & \# & \# & \# \\
\hline
\end{tabular}

** Correlation is significant at the .01 level (2 tailed).

* Correlation is significant at the .05 level (2 tailed).

\#The parameter is set to 0 because it is redundant.

in Nepal when compared with the studies done in other Southeast Asian countries such as Thailand (12-18\% using NCEP definition) and India (18.3\% using IDF definition) [35]. These findings suggest the need for specific attention to control the disease prevalence in Nepal.

4.5. Limitations. Our study has several limitations that should be considered. Although data were prospectively collected, they may not be generalizable outside of Eastern Nepal. The results did not show substantiate relationship between smoking histories, diet, family history of cardiovascular, and metabolic syndrome. Matched groups may be more appropriate to explore these relationships.

\section{Conclusion}

There was high prevalence of hypertension and obesity in Nepal. High triglycerides and low HDL levels substantially contribute the prevalence of MS in Nepal. Abdominal obesity, with the revised reference values, is an important risk due to its physiological relationship to the other MS risk factors. There was also a high level of blood glucose. The MS prevalence may be due to lack of awareness and unhealthy lifestyles, so health education and more preventive measures should decrease the prevalence of MS and cardiac risks in Nepal.

\section{References}

[1] World Health Organization, Global Health Risks: Mortality and Burden of Disease Attributable to Selected Major Risk, World Health Organization, Geneva, Switzerland, 2009.

[2] J. E. Shaw, R. A. Sicree, and P. Z. Zimmet, "Global estimates of the prevalence of diabetes for 2010 and 2030," Diabetes Research and Clinical Practice, vol. 87, no. 1, pp. 4-14, 2010.

[3] Third Report of the National Cholesterol Education Program (NCEP), "Expert panel on detection, evaluation, and treatment of high blood cholesterol in adults (adult treatment panel III) final report," Circulation, vol. 106, no. 25, pp. 31433421, 2002.

[4] S. M. Grundy, B. Hansen, S. C. Smith, J. I. Cleeman, and R. A. Kahn, "Clinical management of metabolic syndrome: report of the American Heart Association/National Heart, Lung, and Blood Institute/American Diabetes Association conference 
on scientific issues related to management," Arteriosclerosis, Thrombosis, and Vascular Biology, vol. 24, no. 2, pp. e19-e24, 2004.

[5] P. Nestel, R. Lyu, P. L. Lip et al., "Metabolic syndrome: recent prevalence in East and Southeast Asian populations," Asia Pacific Journal of Clinical Nutrition, vol. 16, no. 2, pp. 362-367, 2007.

[6] L. E. Eberly, R. Prineas, J. D. Cohen et al., "Metabolic syndrome: risk factor distribution and 18-year mortality in the multiple risk factor intervention trial," Diabetes Care, vol. 29, no. 1, pp. 123-130, 2006.

[7] P. Poirier and J. P. Després, "Waist circumference, visceral obesity, and cardiovascular risk," Journal of Cardiopulmonary Rehabilitation, vol. 23, no. 3, pp. 161-169, 2003.

[8] B. M. Y. Cheung and G. N. Thomas, "The metabolic syndrome and vascular disease in Asia," Cardiovascular and Hematological Disorders, vol. 7, no. 2, pp. 79-85, 2007.

[9] A. Misra, L. Khurana, S. Isharwal, and S. Bhardwaj, "South Asian diets and insulin resistance," British Journal of Nutrition, vol. 101, no. 4, pp. 465-473, 2009.

[10] E. M. Scott, A. M. Carter, and P. J. Grant, "Diabetes and cardiovascular disease: related disorders created by disturbances in the endogenous clock," Journal of the Indian Medical Association, vol. 106, no. 11, pp. 736-740, 2008.

[11] A. Ringborg, C. Cropet, B. Jönsson, J. J. Gagliardino, A. Ramachandran, and P. Lindgren, "Resource use associated with type 2 diabetes in Asia, Latin America, the Middle East and Africa: results from the International Diabetes Management Practices Study (IDMPS)," International Journal of Clinical Practice, vol. 63, no. 7, pp. 997-1007, 2009.

[12] S. K. Sharma, H. Zou, A. Togtokh et al., "Burden of $\mathrm{CKD}$, proteinuria, and cardiovascular risk among Chinese, Mongolian, and Nepalese participants in the international society of nephrology screening programs," American Journal of Kidney Diseases, vol. 56, no. 5, pp. 915-927, 2010.

[13] A. V. Chobanian, G. L. Bakris, H. R. Black et al., "Seventh report of the Joint National Committee on Prevention, Detection, Evaluation, and Treatment of High Blood Pressure," Hypertension, vol. 42, no. 6, pp. 1206-1252, 2003.

[14] F. Razak, S. S. Anand, H. Shannon et al., "Defining obesity cut points in a multiethnic population," Circulation, vol. 115, no. 16, pp. 2111-2118, 2007.

[15] World Hypertension League News Letter, The Nepal Hypertension Society, vol. 119, pp.1-3, 2008.

[16] A. Vaidya, S. Shakya, and A. Krettek, "Obesity prevalence in nepal: public health challenges in a low-income nation during an alarming worldwide trend," International Journal of Environmental Research and Public Health, vol. 7, no. 6, pp. 2726-2744, 2010.

[17] IDF Diabetes Atlas, International Diabetic Federation, 4th edition, 2009, http://www.diabetesatlas.org/.

[18] "American Heart Association recommendations for normal cholesterol levels," http://www.heart.org/HEARTORG/Conditions/What-Your-Cholesterol-Levels-Mean_UCM_305562_ Article.jsp.

[19] R. De Gaudemaris, T. Lang, G. Chatellier et al., "Socioeconomic inequalities in hypertension prevalence and care: the IHPAF study," Hypertension, vol. 39, no. 6, pp. 1119-1125, 2002.

[20] D. Samal, S. Greisenegger, E. Auff, W. Lang, and W. Lalouschek, "The relation between knowledge about hypertension and education in hospitalized patients with stroke in Vienna," Stroke, vol. 38, no. 4, pp. 1304-1308, 2007.
[21] S. A. Lee, W. Wen, W. H. Xu et al., "Prevalence of obesity and correlations with lifestyle and dietary factors in Chinese men," Obesity, vol. 16, no. 6, pp. 1440-1447, 2008.

[22] A. R. Ness and J. W. Powles, "Fruit and vegetables, and cardiovascular disease: a review," International Journal of Epidemiology, vol. 26, no. 1, pp. 1-13, 1997.

[23] R. H. Unger, "Lipid overload and overflow: metabolic trauma and the metabolic syndrome," Trends in Endocrinology and Metabolism, vol. 14, no. 9, pp. 398-403, 2003.

[24] E. A. Enas, V. Mohan, M. Deepa, S. Farooq, S. Pazhoor, and H. Chennikkara, "The metabolic syndrome and dyslipidemia among Asian Indians: a population with high rates of diabetes and premature coronary artery disease," Journal of the Cardiometabolic Syndrome, vol. 2, no. 4, pp. 267-275, 2007.

[25] R. H. Eckel, S. M. Grundy, and P. Z. Zimmet, "The metabolic syndrome," The Lancet, vol. 365, no. 9468, pp. 1415-1428, 2005.

[26] V. Marks, “The metabolic syndrome," Nursing Standard, vol. 17, no. 49, pp. 37-44, 2003.

[27] H. M. Lakka, T. A. Lakka, J. Tuomilehto, and J. T. Salonen, "Abdominal obesity is associated with increased risk of acute coronary events in men," European Heart Journal, vol. 23, no. 9, pp. 706-713, 2002.

[28] W. H. Pan, W. T. Yeh, and L. C. Weng, "Epidemiology of metabolic syndrome in Asia," Asia Pacific Journal of Clinical Nutrition, vol. 17, no. 1, supplement, pp. 37-42, 2008.

[29] U. Salmenniemi, E. Ruotsalainen, J. Pihlajamäki et al., "Multiple abnormalities in glucose and energy metabolism and coordinated changes in levels of adiponectin, cytokines, and adhesion molecules in subjects with metabolic syndrome," Circulation, vol. 110, no. 25, pp. 3842-3848, 2004.

[30] B. Larsson, K. Svardsudd, L. Welin et al., "Abdominal adipose tissue distribution, obesity, and risk of cardiovascular disease and death: 13 year follow up of participants in the study of men born in 1913," British Medical Journal, vol. 288, no. 6428, pp. 1401-1404, 1984.

[31] P. Bjorntorp, ““ Portal” adipose tissue as a generator of risk factors for cardiovascular disease and diabetes," Arteriosclerosis, vol. 10, no. 4, pp. 493-496, 1990.

[32] A. R. Folsom, L. H. Kushi, K. E. Anderson et al., "Associations of general and abdominal obesity with multiple health outcomes in older women: The Iowa Women's Health Study," Archives of Internal Medicine, vol. 160, no. 14, pp. 2117-2128, 2000.

[33] C. E. Tan, S. Ma, D. Wai, S. K. Chew, and E. S. Tai, "Can we apply the National Cholesterol Education Program Adult Treatment Panel definition of the metabolic syndrome to Asians?" Diabetes Care, vol. 27, no. 5, pp. 1182-1186, 2004.

[34] Y. He, B. Jiang, J. Wang et al., "Prevalence of the metabolic syndrome and its relation to cardiovascular disease in an elderly Chinese population," Journal of the American College of Cardiology, vol. 47, no. 8, pp. 1588-1594, 2006.

[35] S. M. Grundy, "Metabolic syndrome pandemic," Arteriosclerosis, Thrombosis, and Vascular Biology, vol. 28, no. 4, pp. 629636, 2008. 


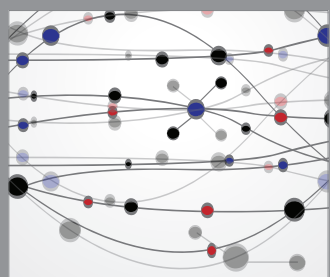

The Scientific World Journal
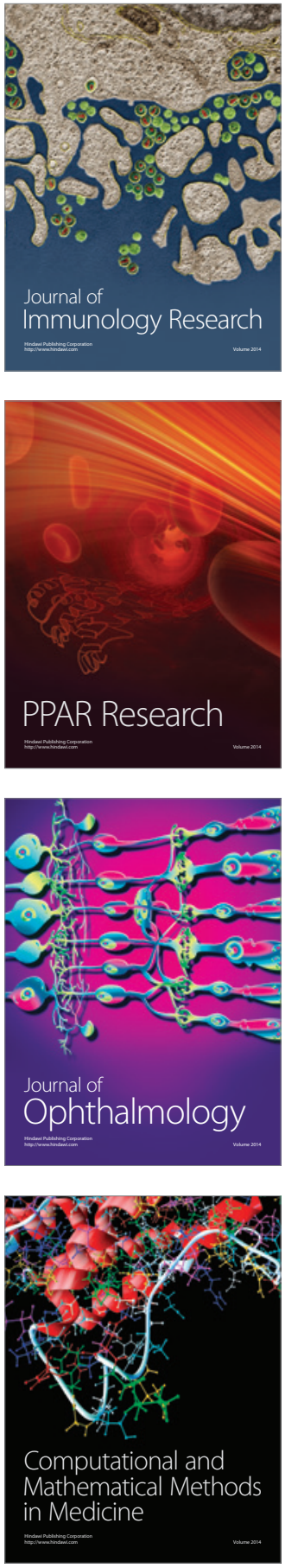

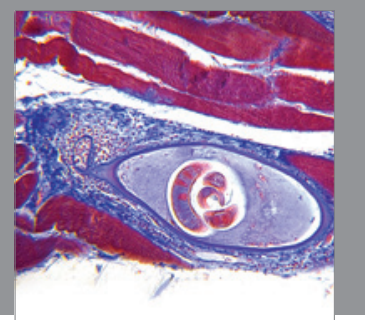

Gastroenterology

Research and Practice
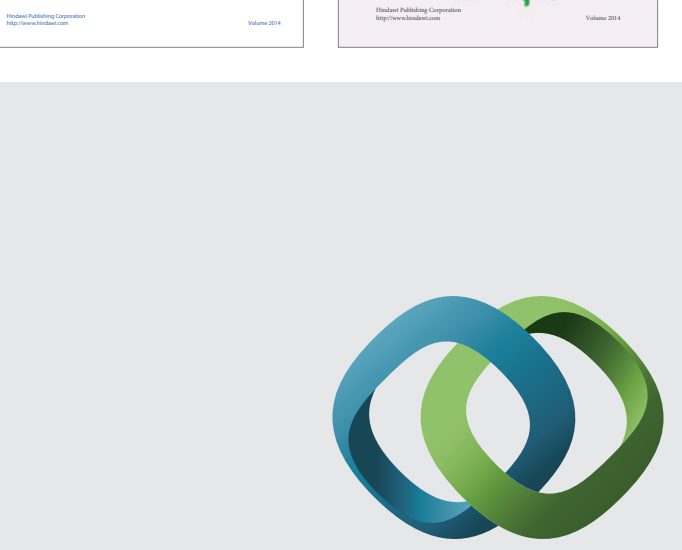

\section{Hindawi}

Submit your manuscripts at

http://www.hindawi.com
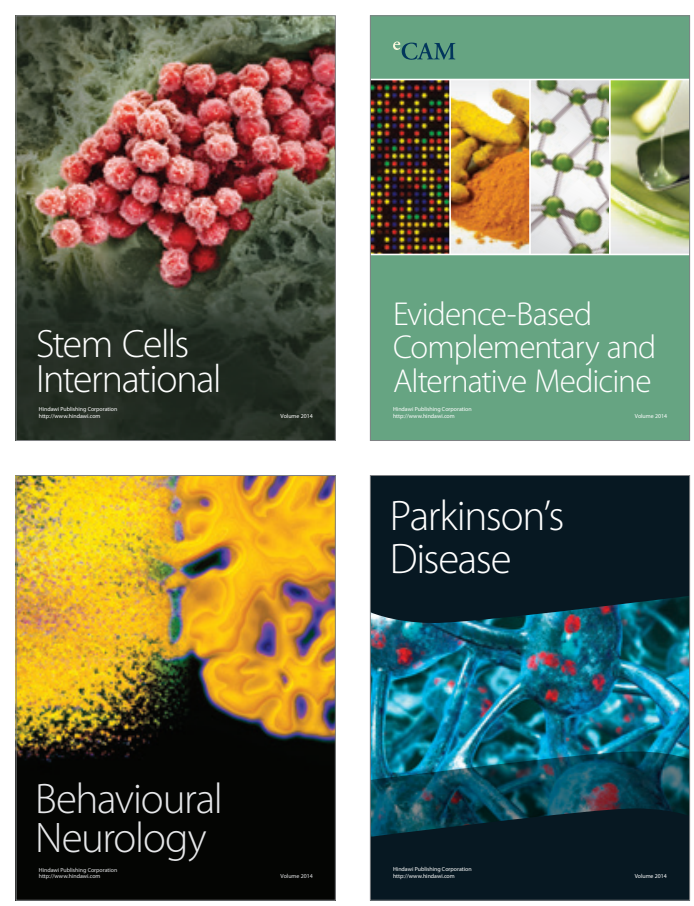

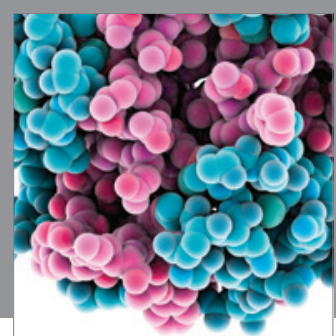

Journal of
Diabetes Research

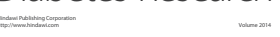

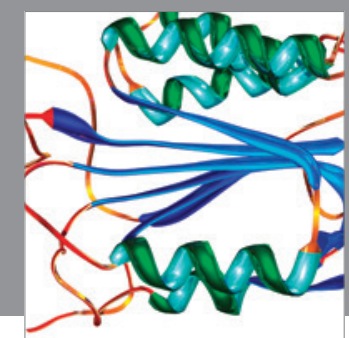

Disease Markers
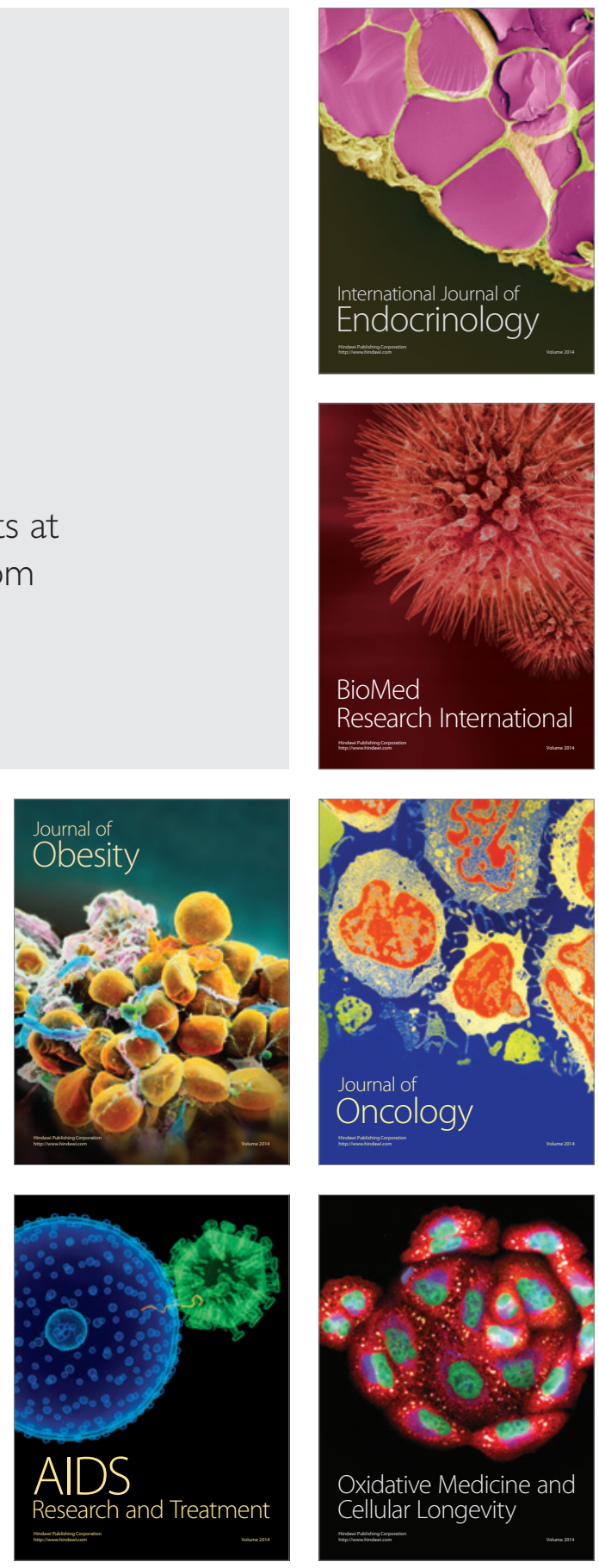